\title{
Depression as a longitudinal outcome and antecedent of preadolescents' peer relationships and peer-relevant cognition
}

\author{
MELANIE J. ZIMMER-GEMBECK, TRACEY A. HUNTER, \\ ALLISON M. WATERS, AND RHIARNE PRONK \\ Griffith University, Australia
}

\begin{abstract}
Using longitudinal data and structural modeling, we investigated bidirectional associations among preadolescents' peer relationships, peer-relevant cognition, and depressive symptoms. Depression was expected to be an outcome and precursor of peer-relevant cognition, and cognition was expected to be an outcome and precursor of being more or less liked by classmates ( peer likeability). We also examined whether cognition mediated the association between peer likeability and depression. Participants were 308 students (mean age $=11.0, S D=0.9$ ) who participated twice during a school year. A third assessment was completed with Grade 5 to 6 students 1 year after the second assessment. The model with bidirectional paths had a good fit to the data, but the most parsimonious model was an "effects" model showing that preadolescents with more depressive symptoms had less positive peer-relevant cognition at later assessments, and that those with more positive peer-relevant cognition were more liked by their peers over time. There were no age differences, some gender differences, and no support for cognition as a moderator of the association between depression and peer likeability.
\end{abstract}

During the transition from childhood to adolescence, relationships with peers are important, the development of social competence is a developmental task, and peer problems are predictive of increasing mental health problems (Bagwell, Schmidt, Newcomb, \& Bukowski, 2001; Bierman, 2003; Parker, Rubin, Price, \& DeRosier, 1995; Rose \& Rudolph, 2006). In the current lon-

We express our thanks to the students, parents, teachers, and principals who agreed to participate in this research. In addition, we thank the undergraduate and postgraduate students who volunteered their data collection skills: Angela Anthonysamy, Dee Bartrum, Karen Gallaty, Dane Halliwell, Michelle Hanisch, Jessica Joyce, Candice Kelly, Anne Lambert, Brett Quayle, Ryan Pinkerton, Rachael Wheeler, and Michalle Wright. Portions of this paper were included in the $\mathrm{PhD}$ thesis of Dr. Tracey Hunter.

Address correspondence and reprint requests to: Melanie J. Zimmer-Gembeck, School of Psychology, Griffith University-Gold Coast Campus, Private Mail Bag 50 GCMC, Southport, Queensland 9726, Australia; E-mail: m.zimmergembeck@griffith.edu.au. gitudinal study, we focused on this important period of social development by investigating the peer relationships, stress, and mental health among children on the threshold of adolescence (preadolescents). Founded in multiple theories, we tested and expected bidirectional associations between peer acceptance ( peer likeability as reported by classmates), self-perceptions of peers relations (peer-relevant cognition), and depressive symptoms.

\section{A Bidirectional Model: The Unified Cause and Effects Models}

Over the last quarter century, there have been many prominent studies that have implicated peer relationships in preadolescents' increasing socioemotional problems (e.g., Boivin, Poulin, \& Vitaro, 1994; Martin, Cole, Clausen, Logan, \& Strosher, 2003; Rudolph, Hammen, \& Burge, 1994, 1997). Yet, not enough research has focused 
on the age period when children are transitioning into adolescence, a time when an escalation of depressive symptoms is expected to occur at the sample or population level (Nolen-Hoeksema, 2001; Nolen-Hoeksema \& Girgus, 1994). In addition, despite the possibility of transactions and bidirectional influences between experiences, cognitions, and mental health (Hammen, 2005; Rudolph \& Asher, 2000; Rudolph \& Clark, 2001; Rutter et al., 1997), few studies have examined whether depressive symptom level is both an outcome and an antecedent of peer problems and related cognitions. This means that it is not clear whether preadolescents who are not as accepted by peers and think negatively about their acceptance and peer relationships have increasing depressive symptoms over time, whether depressive symptoms may actually exist prior to and be a precursor of increasingly negative peer-relevant cognition and peer problems or both. In this study, we founded our model in a developmental psychopathology perspective (Rutter et al., 1997), which prompted a focus on both possibilities simultaneously. This is a dynamic, bidirectional view of the associations between peer relationship stressors, social cognitions and mental health (see also Hammen, 2005). Within such a perspective, objective and subjectively stressful events have been proposed as forces in the development of depression. In turn, depressive symptoms change social cognitive processes and increase the likelihood of stressful environmental experiences, such as rejection or dislike by others (Cicchetti \& Toth, 1995, 1998).

A bidirectional model combines what Hoffman, Cole, Martin, Tram, and Seroczynski (2000) called a "cause model" (p. 652) with their "effects model" (p. 652). In the cause model, depression is expected to be caused by other variables. Depression is modeled as the outcome, and negative peer relationships and peer-relevant cognition are considered predispositional vulnerabilities important to the development of depressive symptomatology. In an effects model, depressive symptom level is expected to have an influence on other variables, such as the lower quality of peer relationships and the formation of negative peer-relevant cognition. In this study, depression was expected to be the precursor of more negative peer-relevant cognition and these cognitions were expected to perpetuate more dislike by peers.

\section{Cause model: Depression as an outcome}

Focusing first on the "cause" portion of the model, our aims were to (a) test whether preadolescents' later depressive symptom level is associated with earlier peer-relevant cognition and peer likeability and (b) determine whether cognition is a mediator of the longitudinal association between peer likeability and depressive symptoms over time. These aims have a basis in theories that have identified mental health problems as outcomes of environmental stressors and individual's appraisals, attitudes, and perceptions (Cole, Martin, Peeke, Seroczynski, \& Hoffman, 1998; Hoffman et al., 2000). Similar to these views and of particular relevance here, models have proposed "psychopathology as a consequence of disturbances in the peer system" (Rudolph \& Asher, 2000, p. 159), and there are multiple studies that have provided evidence for linkages between peer problems and maladaptation (e.g., Boivin et al., 1994; Martin et al., 2003). For example, children and adolescents who are rejected or are less liked have been found to have relatively more depressive symptoms than others their age (Boivin et al., 1994; Harter \& Whitesell, 1996; Hecht, Inderbitzen, \& Bukowski, 1998; Panak \& Garber, 1992; Rudolph et al., 1994, 1997).

Even though how much one is liked or disliked by his/her peers has been found to covary with mental health, perceptions of acceptance and one's relationships with peers also are important to consider. In this study, we proposed a path model that included preadolescents' peer-relevant cognition (perceptions of social acceptance and about the interactions they have with peers) as a mediator of the association between actual peer likeability and depressive symptoms. This mediational pathway originated from two theories: Harter's (1999) theory of the development of the self-concept and sociometer theory (Leary \& Downs, 1995; Leary, Schreindorfer, \& Haupt, 1999). Both theories emphasize the importance of being accepted by others in shaping perceptions of social competence, acceptance, self-worth, 
and mental health. Hence, actual social experience and perception of social acceptance should covary and evidence supports this association. In numerous studies, children or adolescents who were rated by others as relatively more disliked also were more likely to perceive that they had problems with peer relationships: they had more negative views of their peers, and perceived they were less accepted and competent with peers (Crick \& Ladd, 1993; Rudolph et al., 1995).

The theories described above also supported our expectation that depressive symptoms would be an outcome of actual peer acceptance and peer-relevant cognition. For example, in sociometer theory, negative affect has been proposed as an outcome of environmental cues of being ignored or rejected and the perception of a lack of belonging and acceptance by others (Baumeister \& Leary, 1995). Recent studies have supported these hypotheses by showing how depressive symptoms are associated with negative social experiences and individual cognitions, perceptions and attitudes (Caldwell, Rudolph, Troop-Gordon, \& Kim, 2004; Zimmer-Gembeck, Hunter $\&$ Pronk, 2007). The identification of perception of peer relationships as a mechanism accounting for the association between peer likeability and depressive symptoms of children and adolescents has been most promising (Bierman, 2003; Rudolph et al., 1997; Rudolph \& Clark, 2001). In these previous studies, perception of peer relationships has been defined as beliefs and schemas that individuals possess regarding their social worlds, particularly their relationships with others, reasoning in social situations, and views of one's own social behaviors.

As has been found with self-perceptions of social acceptance, more negative perceptions of peer relationships have been associated with more depressive symptoms and increasing levels of depressive symptoms over time (Cole et al., 1998; Hoffman et al., 2000). In fact, it has been found that negative peer-relevant cognition is more strongly linked to depression when compared to self-related cognition (e.g., Rudolph et al., 1997; Weisz, Rudolph, Granger, \& Sweeney, 1992) and support from friends (Harter, 1990). Furthermore, empirical evidence has shown that perceptions in peersalient domains, such as perceived social acceptance by peers, are more strongly related to depressive symptoms when compared to perceptions about competence in other domains, such as scholastic competence (Harter \& Whitesell, 1996).

\section{Effects model: Depression as a precursor}

Hammen (2005) has described a stress generation model, which identifies how depressive symptoms prompt reactions from others, causes selection in and out of particular environments, and impacts social experiences. This view builds on theory explaining how people with depression can create their own negative experiences (Coyne, 1976; Joiner, 2000; Sacco \& Dunn, 1990; Segrin, 2001). In multiple studies, depression has been associated with cognitive patterns (e.g., Gleicher \& Weary, 1991; Joiner, Wingah, Gencoz, \& Gencoz, 2005). These cognitive patterns may prompt negative social behaviors and result in erosion of the positive perceptions of others. Self-verification theory is one perspective that clearly delineates how depression can be part of a cycle that elicits interpersonal rejection via negative feedback seeking and negative appraisals of others (Joiner, 1995; Weinstock \& Whisman, 2004). Applying this to relationships with peers, childhood and adolescents can be susceptible to mental health problems when rejected by their peers, but they also can contribute by having thoughts and behaviors that create additional problems with others.

Consistent with a stress generation model, studies have reported that depressive symptoms precede peer rejection and deficits in social competence (e.g., Levendosky, Okun, \& Parker, 1995; Vernberg, 1990), but we expect that this association may be better explained by considering the role of peer-relevant cognition. This expectation has received some empirical support. The Reformulated Social Information Processing Model (Crick \& Dodge, 1994) provides support for this expected transactional nature of peer-relevant cognition, peer stress (such as lack of peer likeability), social behaviors, and mental health. In this theory, children and adolescents who hold negative views of their peers are expected to engage in behaviors that impact their acceptance by others. Empirical support for this hypothesis was found in a study of preadolescents with negative views of themselves within the 
peer context (Caldwell et al., 2004). Young people with more negative views were increasingly likely to disengage from relationships, leading to higher levels of peer stress over a 1.5-year period. In addition, the reverse was true; experiences of peer stress led to social disengagement and increasingly negative peer-relevant cognition.

\section{Age and Gender as Moderators}

Age

Age was tested as a moderator of associations between peer likeability, peer-relevant cognition, and depressive symptoms. We expected that associations between peer likeability and peerrelevant cognition and between peer-relevant cognition and depressive symptoms would be found across age groups, but would be stronger in older compared to younger participants.

The participants in the current study were in Grades 5, 6, and 7 (between 9.5 and 13.2 years of age). Because most of the participants would not be expected to be postpubertal, for simplicity we refer to the participants as preadolescents. Preadolescence is an important transitional period for socioemotional, cognitive, and biological development (Feldman \& Elliot, 1990). Major depressive disorder is identified in approximately $0.4 \%$ to $2.5 \%$ of children and $0.4 \%$ to $8.3 \%$ of adolescents, and it has lifetime prevalence in adolescents of $15 \%$ to $20 \%$ (Birmaher et al., 1996). Yet, in studies (most from North America), rates of depression increase during the transition from childhood to adolescence, and we targeted this age period to capture the first signs of increases in depressive symptomatology, especially for girls compared to boys (Nolen-Hoeksema, 2001; Rudolph, 2002).

There are a number of specific changes during this age period that led to our prediction that the strength of model pathways would be moderated by age. First, there are changes in peer relationships and friendship, with age changes in understanding of others and conceptions of social relationships and acceptance (Harter, 1999) and young people increasingly turning to their peers rather than parents for support, intimacy, and companionship (Berndt, 1996, 2004; Bukowski, 2001; Furman \& Buhrmester, 1992; Hartup, 1989). Such understanding of others and relation- ships with peers are associated with social developmental and psychosocial functioning (Bagwell et al., 2001; Harter, 1999). This implies that there should be age-related increases in the association between peer acceptance, peer-relevant cognition, and depressive symptoms. This expectation is strengthened by the evidence of age-related increases in depressive symptoms during the transition to adolescence (Nolen-Hoeksema, 2001).

\section{Gender}

Participant gender also can be an important moderator of the bidirectional model pathways hypothesized in the current study (Crick \& ZahnWaxler, 2003; Rose \& Rudolph, 2006). Hence, we tested gender as a moderator, and expected that longitudinal model pathways would be stronger for girls than for boys. However, these expectations were relatively tentative, because the evidence shows that gender moderation is more consistent when participants are all over about age 11 or 12 , depends on the particular measure of peer stress, and may depend on the mental health outcome measured. First, regarding age, females have higher rates of depression than males by about age 13-14, but probably before (Cyranowski, Frank, Young, \& Shear, 2000; Prinstein, Borelli, Cheah, Simon, \& Wargo Aikins, 2005; Wichstrom, 1999). Theories and some empirical research link these differences to girls' greater exposure to interpersonal stress, elevated reactivity to these stressors when they occur, greater affiliative focus, and/or different responses to peer stress compared to boys (e.g., Bukowski \& Adams, 2005; Crick \& Zahn-Waxler, 2003; Cyranowski et al., 2000; Nolen-Hoeksema, 2001; Rose \& Rudolph, 2006; Rudolph, 2002). Regarding the particular aspects of peer stress and mental health measured in the current study (peer likeability and depressive symptoms), researchers have reported that likeability by peers is salient to both boys and girls, but that the mental health outcomes may differ. Girls may develop depressive symptoms when they experience peer stress, whereas boys may exhibit externalizing behaviors rather than depressive symptoms (Lopez \& DuBois, 2005; Oldehinkel, Rosmalen, Veenstra, Kornelis Dijkstra, \& Ormel, 2007). However, much of this evidence for gender difference and moderation is found in studies 
of adolescents, and one recent study of children found no support for gender as a moderator of associations between peer-relevant social cognitions and depressive symptoms (Kistner, David-Ferdon, Repper, \& Joiner, 2006).

In sum, evidence for why and when there might be a gender difference in the influence of interpersonal processes on depression is not yet clear. Given that our participants were aged between 9.5 and 13.2 years, we expected that participant gender would moderate the association between peer likeability and peer-relevant cognition. This hypothesis was strengthened by the specific measure of interpersonal stress we focused on in the current study, peer likeability, which has been found to be more important to girls' than boys' social cognitions and associated behaviors with peers (Bukowski \& Adams, 2005; Prinstein et al., 2005; Rose \& Rudolph, 2006). Supported by previous evidence with a slightly older sample (Prinstein et al., 2005), we also expected that gender would moderate the association between peer-relevant cognition and depressive symptoms, with a stronger association among girls compared to boys.

\section{Diathesis-Stress: Peer-Relevant Cognition as a Moderator}

Moderator models, or diathesis-stress models, have pointed to cognitive factors as interacting with stressful experiences to predict depression. Theory suggests that peer-relevant cognition plays such a moderating role. Diathesis-stress models (Rudolph, 2002; Rudolph \& Asher, 2000) and other vulnerability-stress models (Davila, Ramsay, Stroud, \& Steinberg, 2005) provide one approach to the study of peer relationships, cognitions, and depressive symptoms. Using this approach, negative relationship cognitions have been described as exacerbating the association between interpersonal stress and mental health outcomes. In studies of adolescents (Moran \& Eckenrode, 1991) and university students (Alloy, Abramson, \& Francis, 1999), having a more negative cognitive style has been shown to increase vulnerability to mental health problems in the face of stress. When compared to studies of older adolescents, fewer studies of children and preadolescents have found social cognitions to play a moderating role in the stress-symptom link (see Rose \& Rudolph, 2006, for a review). We tested a diathesis-stress model in the current study by considering peerrelevant cognition as the vulnerability factor that could moderate the association between low peer likeability (i.e., a measure of peer stress) and depressive symptoms.

\section{Summary of the Present Study}

To summarize, our purpose was to test pathways between preadolescents' peer likeability, peer-relevant cognition, and depressive symptoms. We began with testing two of our primary hypotheses using latent-variable path models, and expected to find evidence of both a cause and an effect model of depression. It was hypothesized that peer likeability would be associated with changes in depressive symptoms over time, and preadolescents' peer-relevant cognition would mediate this temporal association between peer likeability and depressive symptoms. The "effects model" paths from preadolescents' Time 1 (T1) depressive symptoms to Time 2 (T2) peer-relevant cognition, and from $\mathrm{T} 1$ peer-relevant cognition to $\mathrm{T} 2$ peer likeability were also estimated in this model, and we expected to find these converse associations. Moreover, we anticipated that simultaneously freeing both cause and effects pathways (a bidirectional model) would provide a good fit to the data, and that a more parsimonious "cause model" or "effects model" would each decay model fit when compared to the bidirectional model.

After these models were tested, we examined age and gender as moderators. We focused on age first, beginning with the bidirectional model and constraining all paths to be equal between age groups. We next freed directional paths and covariances between latent constructs, and compared the fit of this model to the previous model. This comparison allowed us to conclude whether age was a moderator. Turning to participant gender as a moderator, we fit models that paralleled those for age groups. Finally, we determined whether a diathesis-stress model added to our prediction of preadolescents' depressive symptoms by testing peer-relevant cognition as a diathesis (vulnerability) that interacts with peer likeability in the prediction of depressive symptoms over time. This was tested by (a) forming groups of participants with negative or positive 
peer-relevant cognition and using a procedure that paralleled the one used for testing age and gender moderation, (b) forming interaction terms to use as measured indicators of a latent interaction term within a structural equation model (Jaccard \& Wan, 1995), and (c) regressing depressive symptoms on peer likeability, peer-relevant cognition, and the interaction between them (Peer Likeability $\times$ Peer-Relevant Cognition; Jaccard, Turrisi, \& Wan, 1990).

\section{Method}

\section{Participants}

Students $(N=334)$ from 18 classrooms in three primary schools in Queensland, Australia, had parent consent and assented to participate in the study. The consent rate was $70 \%$. Participants who had obtained consent to participate at T1 were eligible to participate in a follow-up assessment 6 months later. Of the original 334 students, 308 had complete assessments at T2 (92\% retention). Participants were in Grades $5(n=95), 6$ ( $n$ $=105)$ and $7(n=108)$, with $47 \%$ boys and $53 \%$ girls. The mean age of participants at time of recruitment was $11.0(S D=0.9)$, including 55 children who were age 9,91 children age 10,106 children age 11, 53 children age 12, and 3 children who had just turned 13 years of age. Mean age of participants at T2 was $11.5(S D=0.9)$. Primary schools in Queensland include Grades 1 through 7 , and students are about 1 year younger when compared to the same grade level in many other countries (e.g., some European countries, United States, Canada). Therefore, the current sample comprised preadolescents in the final 3 years of primary school. The schools were moderate in size, with student populations of 500 to 800 students. Two schools served primarily low- to middle-income areas, whereas the third school had a primarily middle-income student population.

The participants were representative of their community. Most participants were White Australian $(88 \%)$, whereas $7 \%$ of participants were Aboriginal Australian or Pacific Islander (e.g., Maori, Samoan), 3\% Asian, and 2\% African or South American. Most mothers had completed high school only (25\%), left high school in 10 th grade $(31 \%$, which is relatively common in Australia), or left prior to 10th grade (9\%).
Of other mothers, $22 \%$ had completed vocational school after leaving high school after 10th or 12th grade, and $13 \%$ had completed university study. Fathers' highest education levels were similar: high school completion only, 31\%; 10th grade completion only, $29 \%$; left high school prior to 10th grade, $8 \%$; vocational training, $21 \%$; university study, $11 \%$. Most children lived with two parents $(68 \%)$ or with mother only $(27 \%)$.

Eleven participants (3\%) who were missing one or two items on the self-report measures were maintained in the sample by calculating total scores based on remaining items. With the current sample size, this small amount of missing data was distributed randomly and the selection of a particular technique to compensate for missing data to the exclusion of others (e.g., imputations) would not be expected to influence results (Tabachnick \& Fidell, 2001).

Given the number of variables to be included in structural equation models and the associated need for a large sample size, most of the analyses presented here are based on these 308 participants with two waves of data. However, a final model with three waves of data was tested to validate the findings of models with two waves of data. This model was tested with 146 students (51\% boys) who participated in three waves of data collection. The third wave of measurement was completed in the same primary schools 1 year after T2. Because the participating schools included Grades 1 through 7 , 146 participants (73\%) who were in Grades 5 and 6 at $\mathrm{T} 1$ and $\mathrm{T} 2$ were followed the next school year, while they were still attending the same primary schools (Grades 6 or 7).

Participants lost after the first assessment $(n=$ 26) were significantly less liked by their classmates compared to others $(M=2.89, S D=$ 0.51 vs. $M=3.26, S D=0.59), F(1,333)=$ $9.28, p<.01$. No other test of group difference was significant. Other than an age difference, there were no significant group differences when those who were included in the third wave of data collection were compared to those who did not participant beyond the second assessment.

\section{Measures}

Depressive symptoms. The Children's Depression Inventory (CDI; Kovacs, 1985) was used 
to assess depressive symptoms. The CDI is a 27-item self-report questionnaire designed to measure the presence and severity of a wide range of depressive symptoms. Respondents were required to choose one of three statements. An overall score was obtained by summing responses to all items. Possible scores range from a minimum of 0 to a maximum of 54, with higher scores reflecting more severe depressive symptoms. This scale had high internal consistency at T1 $(\alpha=.91)$, T2 $(\alpha=.89)$, and T3 $(\alpha=.89)$. Example items from the CDI are (a) "I feel like crying every day," (b) "I feel like crying many days," and (c) "I feel like crying once in a while." At T2, 16\% of participants scored above the clinical cutoff for depression (and their parents were informed) and 21\% were high, but in the subclinical range.

Three subscale scores from items on the CDI were formed (i.e., referred to as parcels; see Little, Cunningham, Shahar, \& Widaman, 2002). There are many debates about how to make decisions about the measured indicators to use for structural equation modeling latent constructs. For example, there are differing opinions about whether it is best to maintain individual items or whether it is best to identify groups of items ("parcels") that are combined prior to their use as measured indicators. Methodologists have also considered how to parcel data under different conditions (Little et al., 2002; Landis, Beal, \& Tesluk, 2000). Given the sample size and the multidimensionality of measured constructs, parcelling of the CDI (as opposed to maintaining all 27 items as indicators of depressive symptoms) was used in the current study.

The most common procedure (described by Landis et al., 2000) for constructing parcels was used. The loadings of CDI items on a single factor were estimated using principal axis factoring. Items with the highest and lowest loadings were placed into one composite; items with the next highest and lowest loadings were placed into the second composite, and so on until three composite measures were formed. Each composite had nine items, which were averaged to form three depressive symptoms subscale scores for each participant. Interitem correlations ranged from .72 to .77 . These three composite scores were used as measured indicators of depressive symptoms when fitting structural equation models. In other analyses total CDI scores were used.

Peer likeability. Participants rated each classmate on a 5-point scale ranging from 1 (do not like at all), to 5 (like a lot). On average, classrooms had 20 students, so each student received 19 ratings. Ratings were averaged so that each participant received a continuous score between 1 and 5, and the scores were standardized prior to analyses. Higher scores indicated that a child was more liked by classmates. We refer to this measure as "peer likeability" for brevity.

Actual levels of peer acceptance or rejection and peer likeability are usually assessed by asking students to report their opinions of all others in their classroom or grade (Asher \& Dodge, 1986; Cillessen \& Bukowski, 2000; DeRosier \& Thomas, 2003). To assess peer likeability, researchers usually ask all students in the classroom to rate how much they like their classmates. Ratings range from low liking to high liking or from very disliked to very liked. Using classmate-reported ratings of peer likeability has been encouraged (Hymel, Rubin, Rowden, \& LeMare, 1990), as this method obtains information about how much each student is liked or disliked by classmates in general. Upon further examination, the measure of peer likeability approximated the general status of each child among all other students in a classroom. At T1, most participants received a wide range of ratings from others; $83 \%$ received at least one rating of 1 (do not like at all) and $92 \%$ received at least one rating of 5 (like a lot $)$. On average, $15 \%(S D=14 \%)$ of an individual's ratings were 1 (do not like at all), whereas $20 \%$ (13\%) were ratings of 5 (like a lot). When a participant did not receive all possible ratings, she/he was more likely to be one of the few students liked by all other classmates.

Peer-relevant cognition. Two measures were used to assess self-perceptions of social acceptance and their perceptions of their relationships with peers. First, the Perception of Peers and Self Questionnaire (POPS; Rudolph, Hammen, \& Burge, 1995; 30 items) was used to measure perceptions of peer relationships and the self when interacting with peers. The "peer" subscale measured generalized perceptions of peers and friendship along dimensions such as depen- 
dability, supportiveness, and empathy. The "self" subscale measured perceptions of self and success in the context of peer relationships, and tapped both what participants believe about themselves (a cognitive component) and how they feel about themselves within the peer domain (an affective component). The peer and self subscales contained 15 items each. High internal consistency was found for the peer (T1: $\alpha$ $=.79, \mathrm{~T} 2: \alpha=.83, \mathrm{~T} 3: \alpha=.78)$ and self (T1: $\alpha$ $=.79, \mathrm{~T} 2: \alpha=.85, \mathrm{~T} 3: \alpha=.74)$ subscales. An example item from the peer subscale is, "Other kids will try to put you down or tease you if they have a chance." An example item from the self subscale is, "When other kids do not want to be around me, it's probably because there's something wrong with me." Responses ranged from 1 (almost never) to 5 (almost all the time). Items were averaged after reversing items so that higher scores indicated more positive perceptions.

Second, the six-item social acceptance scale of The Self-Perception Profile for Children (SPPC; Harter, 1982) was used to assess selfperceptions of social acceptance by peers. Each student was asked to select one of two opposing statements that is most like him/her and rates whether this statement is "sort of true for me" or "really true for me." An example item is, "some kids find it hard to make friends BUT other kids find it pretty easy to make friends." Item responses were averaged to form social acceptance scores (range $=1-4$ ). Higher scores reflect higher self-perceived social acceptance by peers. Social acceptance had high internal reliability in the current study (T1: $\alpha=.81, \mathrm{~T} 2: \alpha$ $=.84$ ). Items were averaged, and scores were formed so that higher scores indicated perception of more social acceptance by peers.

A total score was calculated to reflect average peer-relevant cognition across the three measures. Participants' scores on the peer and self subscales of the POPS and the social acceptance subscale of the SPPC were standardized and averaged, with higher scores reflecting more positive peer-relevant cognition. This measure was used when testing peer-relevant cognition in simple group comparisons, when testing cognition as a moderator of the association between peer likeability and depressive symptoms, and when testing the threewave model.

\section{Procedure}

Following ethical approval, questionnaires were administered to all participants who had parent consent and gave their assent to participate. Data collection was completed in regular classrooms during school hours. Participants were offered candy and a pencil as tokens of appreciation for their participation. All self-report and peer nomination questionnaires were read aloud to students for ease of administration, and total testing time was approximately $45 \mathrm{~min}$. Following data collection, individual debriefing was made available to students. Students were advised to approach parents and the school guidance officer for any ongoing concerns. Parents of students who scored in the clinical range on the CDI were contacted by phone after the questionnaire administration, informed of their children's elevated depressive symptom scores, possible reasons for elevated scores were discussed, and referral options were given on request.

\section{Results}

\section{Descriptive analyses, zero-order correlations, and stabilities}

Means and standard deviations of all variables are presented in Table 1. Correlations between peer likeability, peer-relevant cognition, and depressive symptoms at $\mathrm{T} 1$ and $\mathrm{T} 2$ also are presented in Table 1. Stabilities of $\mathrm{T} 1$ and $\mathrm{T} 2$ measures are shown on the diagonal of Table 1. Correlations between measures included in the threewave model are shown in Table 2. To correct for positive skew in depression scores, square root transformations were applied. This resulted in distributions that were closer to approximating the normal curve. Descriptive statistics for untransformed measures are presented in Tables 1 and 2 to allow for comparisons with past research. Transformed variables were used for correlations and structural equation models.

\section{Preadolescent biological gender and grade level comparisons}

Gender and age groups were compared prior to testing hypotheses. There were no gender differences (see Table 3). Age group comparisons 
Table 1. Descriptive statistics and zero-order Pearson correlations between all measured variables at Time 1 and Time $2(N=308)$

\begin{tabular}{|c|c|c|c|c|c|c|}
\hline & 1 & 2 & 3 & 4 & 5 & 6 \\
\hline $\begin{array}{l}\text { 1. Depressive } \\
\text { symptoms }\end{array}$ & $.70 * *$ & $-.27 * *$ & $-.61 * *$ & $-.64 * *$ & $-.60 * *$ & $-.68 * *$ \\
\hline 2. Peer likeability & $-.29 * *$ & $.76 * *$ & $.34 * *$ & $.29 * *$ & $.45 * *$ & $.40^{* *}$ \\
\hline 3. Perception of peers & $-.55 * *$ & $.37 * *$ & $.60 * *$ & $.72 * *$ & $.61 * *$ & $.88 * *$ \\
\hline $\begin{array}{l}\text { 4. Perception of self } \\
\text { with peers }\end{array}$ & $-.64 * *$ & $.30 * *$ & $.67 * *$ & $.64 * *$ & $.69 * *$ & $.90 * *$ \\
\hline $\begin{array}{l}\text { 5. Perceived social } \\
\text { acceptance } \\
\text { 6. Total peer-relevant }\end{array}$ & $-.58 * *$ & $.43 * *$ & $.58 * *$ & $.64 * *$ & $.67 * *$ & $.87 * *$ \\
\hline cognition $^{a}$ & $-.67 * *$ & $.42 * *$ & $.86^{* *}$ & $.89 * *$ & $.85^{* *}$ & $.71 * *$ \\
\hline$M(S D)$, Time $1^{b}$ & 8.65 (7.15) & $0.0(1.0)$ & $4.04(0.42)$ & $4.13(0.51)$ & $3.05(0.73)$ & $0.00(0.87)$ \\
\hline$M(S D)$, Time $2^{b}$ & 7.78 (7.37) & $0.0(1.0)$ & $4.12(0.44)$ & $4.21(0.48)$ & $3.16(0.71)$ & $-0.01(0.89)$ \\
\hline
\end{tabular}

Note: Time 1 correlations are below the diagonal, and Time 2 correlations are above the diagonal. Stabilities are shown on the diagonal.

${ }^{a}$ The average of the standardized perception of peers, perception of self with peers, and perceived social acceptance.

${ }^{b}$ Untransformed values of depressive symptoms and children's behaviors. Correlations were computed with transformed values.

$* * p<.01$.

were conducted after categorizing participants as age $9-10(n=145)$ or age $11-13(n=$ 163). There was one significant difference; older participants were more liked, on average, than younger participants at $\mathrm{T} 1(p<.01)$.

\section{Model testing}

AMOS with maximum likelihood estimation was used to estimate structural equation models (SmallWaters Corporation, 1999). Model fit was assessed with commonly used indices, including the chi-square test statistic and associated level of significance and the comparative fit index (CFI; Bentler \& Bonett, 1980). The root mean square error of approximation (RMSEA; Browne \& Cudeck, 1993) provided an estimate of error because of approximate fit of the models. The CFI is more acceptable as values approach 1 ; values over .95 are considered indication of very good model fit $(\mathrm{Hu} \&$ Bentler, 1999). RMSEA values below .05 are considered good, values between .05 and .08 are considered indicative of fair fit, and values between .08 and .10 are considered an indication of mediocre fit (Kaplan, 2000). Critical ratios were used to determine significance of model paths ( $t$ test values above an absolute value of 1.96).
Bootstrapping was applied to obtain standard errors and 95\% confidence intervals (CIs) of path coefficients (Shrout \& Bolger, 2002; Zimmer-Gembeck, Chipuer, Hanisch, Creed, \& McGregor, 2006). The method involves taking repeated, random selections of cases from a study sample with replacement after each sampling. This allows an examination of the distribution of a test statistic, and the calculation of an average, median and/or standard error of a test statistic. Bootstrapping can be used in structural equation modeling and is especially helpful in models when the sample size is small to moderate $(N<$ 400) and variables are not normally distributed (for further information, see Zimmer-Gembeck et al., 2006).

\section{Two-wave longitudinal models}

Three models were fit to the first two waves of data. First, we fit a model to test bidirectional associations between peer likeability and peer-relevant cognition, and between cognition and depressive symptoms (see Figure 1). Second, a model was fit to test a "cause" model and the mediational role of peer-relevant cognition only. In this model, two directional paths were constrained to 0 to estimate only the paths from $\mathrm{T} 1$ peer likeability to $\mathrm{T} 2$ peer-relevant cognition, and from T1 peer- 
Table 2. Correlations between three waves of measured variables

\begin{tabular}{|c|c|c|c|c|c|c|c|c|c|}
\hline & 1 & 2 & 3 & 4 & 5 & 6 & 7 & 8 & 9 \\
\hline \multicolumn{10}{|l|}{ 1. T1 depressive } \\
\hline 2. T2 depressive & & & & & & & & & \\
\hline symptoms & .70 & - & & & & & & & \\
\hline $\begin{array}{l}\text { 3. T3 depressive } \\
\text { symptoms }\end{array}$ & 51 & .69 & - & & & & & & \\
\hline 4. $\mathrm{T} 1$ peer likeability & -.31 & -.25 & $-.15 *$ & - & & & & & \\
\hline 5. T2 peer likeability & -.29 & -.25 & -.24 & .69 & - & & & & \\
\hline 6. T3 peer likeability & -.25 & $-.18 *$ & $-.18 *$ & .54 & .66 & - & & & \\
\hline $\begin{array}{l}\text { 7. T1 peer-relevant } \\
\text { cognition }^{a}\end{array}$ & -.53 & -.49 & -.37 & .33 & .31 & $.19^{*}$ & - & & \\
\hline 8. T2 peer-relevant & .00 & .47 & . & & .51 & .13 & - & & \\
\hline cognition $^{a}$ & -.46 & -.61 & -.45 & .28 & .34 & .30 & .54 & - & \\
\hline $\begin{array}{l}\text { 9. T3 peer-relevant } \\
\text { cognition }^{a}\end{array}$ & -.39 & -.49 & -.64 & $.19 *$ & .25 & .23 & .48 & .50 & ב \\
\hline$M(S D)^{b}$ & $8.77(7.60)$ & $7.64(7.45)$ & $7.21(7.50)$ & $0.0(1.0)$ & $0.0(1.0)$ & $0.0(1.0)$ & & & \\
\hline
\end{tabular}

Note: T1-T3, Time $1-3 ; N=308$ for T1/T2 correlations; $N=146$ for T1/T3 and T2/T3 correlations.

${ }^{a}$ The average of the standardized perception of peers, perception of self with peers, and perceived social acceptance.

${ }^{b}$ Means and standard deviations for the 146 students at each of the three waves of measurement. See Table 1 for means and standard deviations for the $308 \mathrm{~T} 1$ and $\mathrm{T} 2$ participants.

$*_{p}<.05$. All other correlations were significant at $p<.01$.

relevant cognition to $\mathrm{T} 2$ depressive symptoms. Third, a model was fit to test an "effects" model. In this model, two directional paths were constrained to 0 to estimate only the paths from $\mathrm{T} 1$ peer-relevant cognition to $\mathrm{T} 2$ peer likeability, and from $\mathrm{T} 1$ depressive symptoms to $\mathrm{T} 2$ peer-relevant cognition.

The bidirectional model. The bidirectional model provided a good fit to the data on all fit indices: $\chi^{2}(58, N=308)=109.5, p<.01$, $\mathrm{CFI}=.98$, RMSEA $=.054(90 \% \mathrm{CI}=.038$ .069). In this model, we freed stabilities of latent constructs, and freed associations between the disturbances of the three indicators of peerrelevant cognition and the three indicators of depressive symptoms.

As shown in Figure 1, other than stabilities, only two of the four hypothesized directional paths were significantly different from zero. These paths were from the effects model portion of the bidirectional model ( $\mathrm{T} 1$ peer-relevant cognition to $\mathrm{T} 2$ peer likeability and $\mathrm{T} 1$ depressive symptoms to T2 cognitions, each $p<.01$ ). The "cause model" paths from $\mathrm{T} 1$ peer likeability to $\mathrm{T} 2$ cognitions, and from $\mathrm{T} 1$ cognitions to
T2 depressive symptoms were not significantly greater than zero. More positive peer-relevant cognition was associated with greater peer likeability at T2, and those with more depressive symptoms had less positive peer-relevant cognition at T2. Overall, the model accounted for $59 \%$ of the variance in $\mathrm{T} 2$ peer likeability, $62 \%$ of the variance in $\mathrm{T} 2$ peer-relevant cognition, and $60 \%$ of the variance in depressive symptoms.

The cause model, peer likeability, and depression mediated via peer-relevant cognition. We next removed two directional paths to test only the cause model. All fit indices indicated an adequate fit to the data, $\chi^{2}(60, N=308)$ $=125.9, p<.01$, CFI $=.98$, RMSEA $=$ $.060(90 \% \mathrm{CI}=.045-.074)$. The chi-square difference test indicated that this cause model significantly degraded model fit when compared to the bidirectional model, $\chi_{\text {difference }}^{2}(2)=$ $16.4, p<.01$. Although the path from peer-relevant cognition to depressive symptoms was moderate in size $(-.22, p=.057)$, the two cross-lag paths in this cause model were not significantly different from zero $(p>.05)$. 
Table 3. Gender and grade differences in peer likeability, peer-relevant cognition, and depressive symptoms

\begin{tabular}{|c|c|c|c|c|c|c|}
\hline & $\begin{array}{l}\text { Boys } \\
M(S D)\end{array}$ & $\begin{array}{l}\text { Girls } \\
M(S D)\end{array}$ & $F(1,307)^{a}$ & $\begin{array}{l}\text { Age } 9-10 \\
M(S D)\end{array}$ & $\begin{array}{l}\text { Age } 11-13 \\
M(S D)\end{array}$ & $F(2,306)^{a}$ \\
\hline Time 1 & $n=145$ & $n=163$ & & $n=145$ & $n=163$ & \\
\hline Peer likeability & $3.21(0.59)$ & $3.30(0.59)$ & 1.74 & $3.16(0.53)$ & $3.34(0.63)$ & $6.86 * *$ \\
\hline Depressive symptoms & $8.92(6.28)$ & $8.41(7.85)$ & 0.40 & $9.04(7.02)$ & $8.31(7.27)$ & 0.81 \\
\hline Perception of peers & $4.03(0.42)$ & $4.04(0.42)$ & 0.07 & $4.01(0.41)$ & $4.06(0.43)$ & 1.39 \\
\hline $\begin{array}{l}\text { Perception of self with } \\
\text { peers }\end{array}$ & $4.11(0.52)$ & $4.15(0.50)$ & 0.58 & $4.09(0.53)$ & $4.17(0.49)$ & 0.15 \\
\hline $\begin{array}{l}\text { Perceived social } \\
\text { acceptance }\end{array}$ & $3.06(0.68)$ & $3.05(0.77)$ & 0.01 & $3.02(0.73)$ & $3.09(0.72)$ & 0.77 \\
\hline $\begin{array}{l}\text { Time } 2,6 \text { months after } \\
\text { Time } 1\end{array}$ & $n=145$ & $n=163$ & & $n=145$ & $n=163$ & \\
\hline Peer likeability & $3.26(0.61)$ & $3.40(0.60)$ & 3.72 & $3.29(0.62)$ & $3.38(0.60)$ & 1.56 \\
\hline Depressive symptoms & $7.36(6.77)$ & $8.15(7.86)$ & 0.88 & $7.85(7.04)$ & $7.71(7.67)$ & 0.03 \\
\hline Perception of peers & $4.11(0.44)$ & $4.13(0.43)$ & 0.08 & $4.08(0.43)$ & $4.15(0.44)$ & 1.68 \\
\hline $\begin{array}{l}\text { Perception of self with } \\
\text { peers }\end{array}$ & $4.21(0.48)$ & $4.22(0.48)$ & 0.10 & $4.20(0.45)$ & $4.23(0.51)$ & 0.25 \\
\hline $\begin{array}{l}\text { Perceived social } \\
\text { acceptance }\end{array}$ & $3.18(0.68)$ & $3.15(0.74)$ & 0.06 & $3.14(0.72)$ & $3.19(0.71)$ & 0.31 \\
\hline $\begin{array}{l}\text { Time } 3,12 \text { months after } \\
\text { Time } 2\end{array}$ & $n=75$ & $n=71$ & & $n=97$ & $n=49$ & \\
\hline Peer likeability & $3.32(0.54)$ & $3.29(0.64)$ & 0.12 & $3.25(0.53)$ & $3.43(0.68)$ & 3.05 \\
\hline Depressive symptoms & $6.65(5.93)$ & $7.80(8.86)$ & 0.86 & $6.70(7.15)$ & $8.22(8.13)$ & 1.35 \\
\hline Perception of peers & $4.19(0.44)$ & $4.27(0.46)$ & 1.35 & $4.27(0.39)$ & $4.15(0.56)$ & 2.29 \\
\hline
\end{tabular}

${ }^{a} F(1,143)$ at Time 3.

$* * p<.01$.

The effects model. We next reversed the paths in the cause model to test the effects model. All fit indices indicated a good fit to the data, $\chi^{2}(60, N$ $=308)=110.8, p<.01, \mathrm{CFI}=.98, \mathrm{RMSEA}=$ $.058(90 \% \mathrm{CI}=.037-.068)$. The chi-square difference test indicated that this effects model provided a similar model fit when compared to the bidirectional model, $\chi_{\text {difference }}^{2}(2)=1.4, p>.05$, and path estimates for T1 peer-relevant cognition to $\mathrm{T} 2$ peer likeability, and for $\mathrm{T} 1$ depressive symptoms to $\mathrm{T} 2$ peer-relevant cognition were similar to those shown in Figure 1.

Paths between peer likeability and depressive symptoms. Additional paths were estimated to conduct further tests of the model structure. First, we freed the path from T1 peer likeability to $\mathrm{T} 2$ depressive symptoms, but this path was not significantly different from zero (path estimate $=.02, S E=.06,95 \% \mathrm{CI}=-.09$ to .14 ). Second, we then removed peer-relevant cogni- tion from the model and found that the direct effect of peer likeability on depressive symptoms remained small and not significantly different from zero, path estimate $=.02(S E=.05$, $95 \% \mathrm{CI}=-.12$ to .08$)$. Third, we next freed the path from $\mathrm{T} 1$ depressive symptoms to $\mathrm{T} 2$ peer likeability and found little support for an association (path estimate $=.08, S E=.04$, $95 \% \mathrm{CI}=-.00$ to $.15, p=.068)$.

Summary. There was less support for a cause model than for an effects model in which higher T1 depressive symptom level predicted more negative peer-relevant cognition over time (i.e., a decreasing level of perceptions of social acceptance and peer relationships over time) and relatively higher levels of $\mathrm{T} 1$ positive peer-relevant cognition predicted greater peer likeability by T2. In addition, there was little evidence of an association between earlier depressive symptoms and later peer likeability or the converse relationship. 


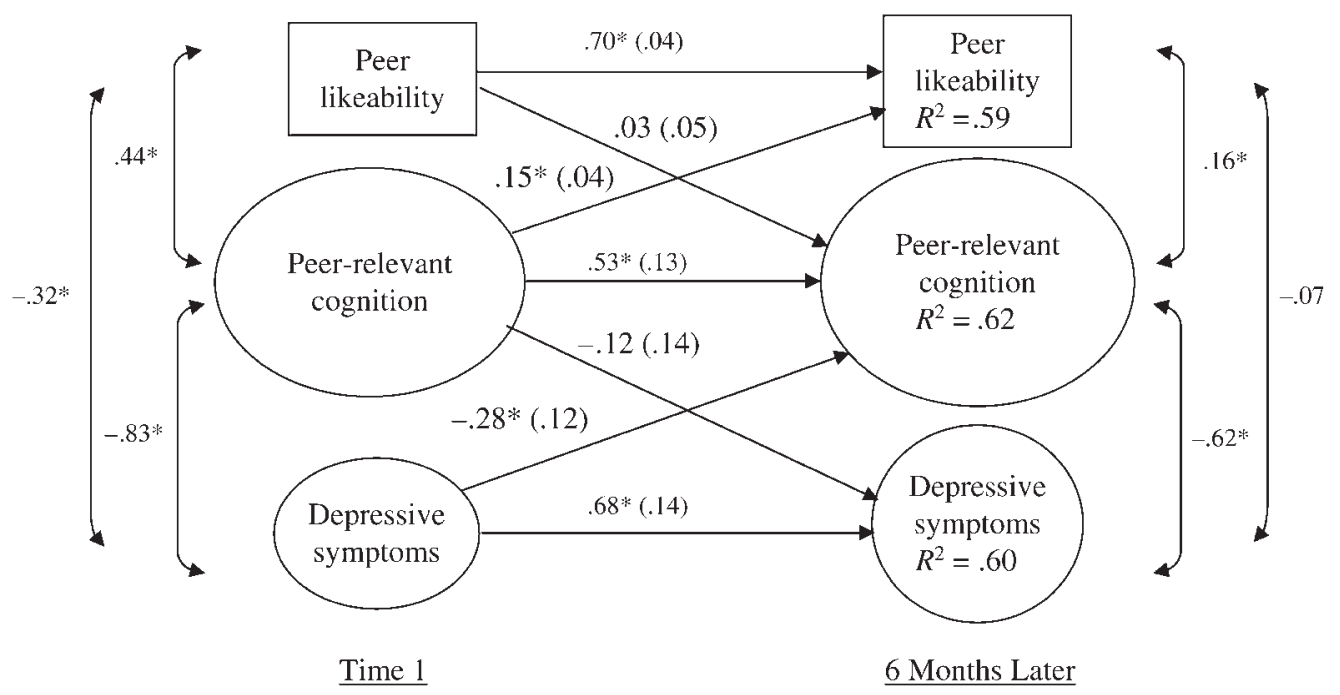

Figure 1. The standardized path coefficients and bootstrapped standard errors of a structural equation model testing a cause and effects model (i.e., a bidirectional model) of peer likeability, peer-relevant cognition, and depressive symptoms. Latent constructs are shown with a circle, and measured variables are shown with a square. $\chi^{2}(58, N=308)=109.5, p<.01, \mathrm{CFI}=.98, \mathrm{RMSEA}=.054(90 \% \mathrm{CI}=.038-.069) . * p<.01$.

Participant age as a moderator: Testing the two-group (age 9-10 vs. age 11-13) models

Two two-group (age 9-10 vs. age 11-13) bidirectional models were estimated to examine hypotheses about participant age as a moderator. The first model constrained all paths to be equal for younger and older participants (equality constraint model). In the second model, we freed directional paths across time and within time covariances between variables to allow different path estimates for younger versus older participants (age-specific model). To improve the stability of estimates for both subgroups, we reduced the number of parameters that required estimation by including only one indicator of peer-relevant cognition (social acceptance).

The fit of each two-group model was good, equality constraint model, $\chi^{2}(64, N=308)=$ $87.0, p=.029, \mathrm{CFI}=.99, \mathrm{RMSEA}=.034$ $(90 \% \mathrm{CI}=.011-.051)$; age-specific model, $\chi^{2}$ $(51, N=308)=78.1, p<.01, \mathrm{CFI}=.98$, RMSEA $=.042(90 \% \mathrm{CI}=.021-.059)$. Nevertheless, the fit of the age-specific model was not significantly different from the fit of the equality constraint model, $\chi_{\text {difference }}^{2}(13)=8.9, p>.05$. In contrast to our hypothesis, estimating different model paths for younger versus older participants did not improve the model fit, and model paths for each age group were similar to those shown in Figure 1 (see Figure 2). There was one notable age difference. Peer likeability was associated with increasing peer-relevant cognition over time among older participants $(.17, p<.01)$, but not younger participants.

\section{Participant gender as a moderator: Testing the two-group (boy, girl) models}

Two two-group (boy/girl) bidirectional models were estimated to examine hypotheses about participant gender as a moderator. These models were parallel to those used to compare age groups. The fit of each two-group model to the data was good, equality constraint model, $\chi^{2}$ $(64, N=308)=120.9, p<.01, \mathrm{CFI}=.97$, RMSEA $=.054$ (90\% CI $=.039-.069)$; gender-specific model, $\chi^{2}(51, N=308)=97.0$, $p<.01, \mathrm{CFI}=.98, \mathrm{RMSEA}=.054(90 \% \mathrm{CI}$ $=.038-.071)$. The gender-specific model provided a significantly better fit to the data than the equality constraint model, $\chi_{\text {difference }}^{2}(13)=$ 23.9, $p<.05$, suggesting that paths do differ for boys compared to girls. In particular, two cross-lag paths, two within time correlations between variables, and two stabilities differed by more than .10 (see Figure 3). Both cross-lag paths 


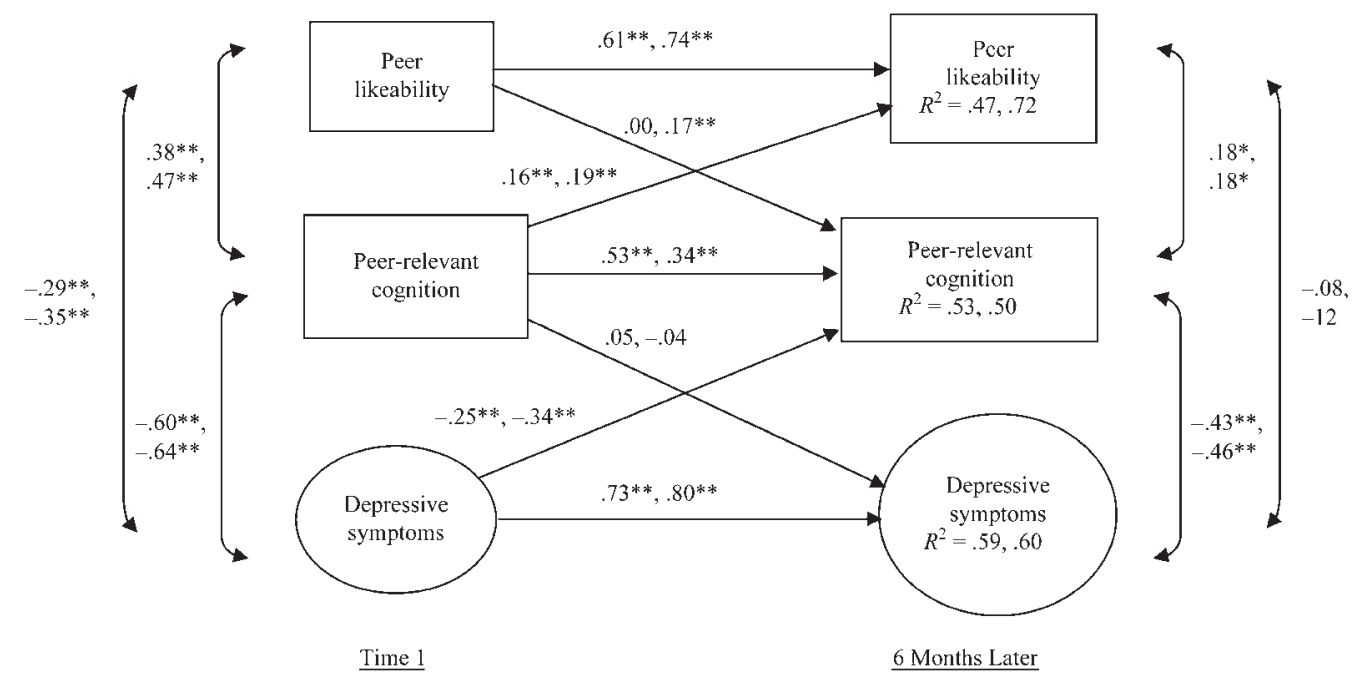

Figure 2. The standardized path coefficients of a structural equation model testing the bidirectional model for two age groups (ages 9-10 vs. ages 11-13). Path estimates for ages 9-10 are followed by path estimates for ages 11-13. Latent constructs are shown with a circle, and measured variables are shown with a square. $\chi^{2}(51, N=308)=78.1, p<.01, \mathrm{CFI}=.98, \mathrm{RMSEA}=.042(90 \% \mathrm{CI}=.021-.059) . * p<.05 . * * p<.01$.

showed stronger associations for boys than for girls; peer likeability was associated with more positive peer-relevant cognition by $\mathrm{T} 2$ for boys but was not significantly associated in girls. In addition, depressive symptoms level was more strongly negatively associated with later peer-relevant cognition for boys than for girls. In contrast, the two within time correlations that differed were stronger for girls than for boys; both of these correlations were between peer-relevant cognition and depressive symptoms. The stabilities that showed gender differences (peer-relevant cognition and depressive symptoms) also were stronger for girls than for boys. Regardless of these gender differences, however, the amount of variance accounted for in each T2 measure was similar for boys compared to girls.

\section{Stress-vulnerability: Peer-relevant cognition as a moderator}

Finally, a two-group (high/low peer-relevant cognition) model was estimated to test a diathesisstress model in which earlier peer-relevant cognition interacts with peer likeability to better account for later depressive symptoms. We classified participants as having a cognitive vulnerability if they had a standardized total peer-relevant cognition score of -.5 or less (i.e., $0.5 S D$ below the mean, $n=107)$. The remaining participants formed a group with more positive peer-relevant cognition. Choosing a threshold of $0.5 S D$ below the mean as a cutoff was necessary to form two groups with adequate sample sizes for analyses. However, this cutoff was necessarily somewhat arbitrary, and could have some limitations for interpretation of findings (Coyne \& Whiffen, 1995; Gibb, Alloy, Abramson, Beevers, \& Miller, 2004). Therefore, to test this further, we analyzed the data in two other ways. First, we used procedures to maintain the continuous scale of the peer-relevant cognition variable (Jaccard \& Wan, 1995). This method involved constructing measured indicators of a latent interaction term for inclusion in the two-group structural equation model. Measured indicators were constructed by multiplying each of three measures of peer-relevant cognition by peer likeability. Second, following procedures described by Jaccard et al. (1990), we formed an interaction term by multiplying the total score for peer-relevant cognition by peer likeability. A hierarchical multiple regression model was used to examine the association between this term and depressive symptoms at T2 after accounting for depression symptoms at $\mathrm{T} 1$. No significant associations emerged from these 


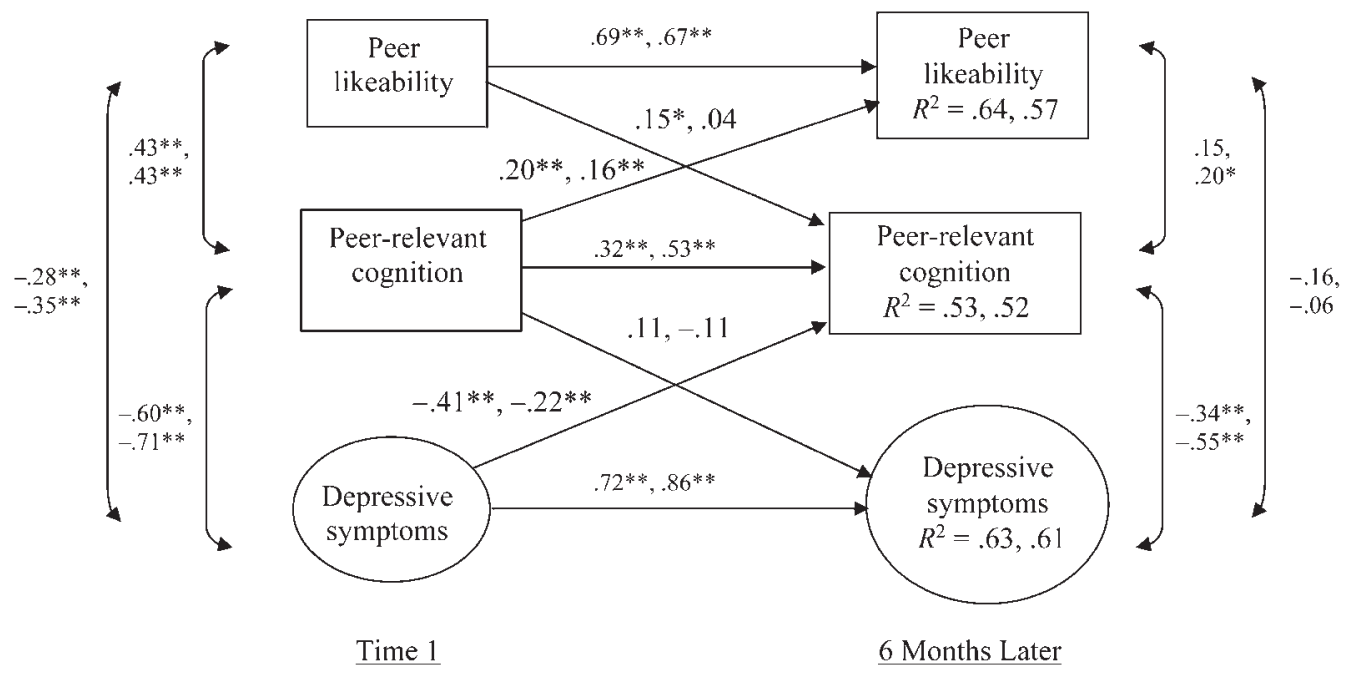

Figure 3. The standardized path coefficients of a structural equation model testing the bidirectional model for boys compared to girls. Path estimates for boys are followed by path estimates for girls. Latent constructs are shown with a circle. Measured variables are shown with a square. $\chi^{2}(51, N=308)=97.0, p<.01$, $\mathrm{CFI}=.98, \mathrm{RMSEA}=.054(90 \% \mathrm{CI}=.038-.071) . * p<.05 . * * p<.01$.

two other approaches, so to allow the most direct comparison with the structural equation modeling results reported earlier, only the first approach (using a threshold of peer-relevant cognition as a vulnerability factor) is reported in detail here.

Although the model fit the data very well, $\chi^{2}$ $(31, N=308)=32.0, p=.42, \mathrm{CFI}=1.00$, RMSEA $=.010(90 \% \mathrm{CI}=.000-.044)$, results did not support a diathesis-stress model. The association between $\mathrm{T} 1$ peer likeability and $\mathrm{T} 2$ depressive symptoms was weak and nonsignificant for both those with and without a cognitive vulnerability, .05 and -.07 , respectively. In addition, the converse association between $\mathrm{T} 1$ depressive symptoms and $\mathrm{T} 2$ peer likeability was weak and nonsignificant for both those with and without a cognitive vulnerability, .00 and -.03 , respectively. We repeated these analyses making the criterion for a vulnerability more stringent (a standardized perceived social acceptance score of -.1 or less, $n=47$ ) and results were similar.

\section{A three-wave bidirectional model}

To validate and extend our findings supporting (a) depressive symptoms as a precursor of lower positive peer relevant cognition and (b) more positive cognition as a precursor of peer likeability, final models were estimated with data collected from the 146 students who participated in three study waves. This model was parallel to the two-wave bidirectional model shown in Figure 1, except that the sample size limited us to specifying measured rather than latent variables. The measured variables were peer likeability ratings, total peer-relevant cognition, and total depressive symptom score. We also tested this model with each of the three components of peer-relevant cognition. All models had adequate fit to the data, and all path estimates were similar across different models, so we report results using the total peer-relevant cognition score to parallel other analyses as closely as possible (see Figure 4).

The three-wave bidirectional model fit the data adequately on all fit indices: $\chi^{2}(13, N=$ $146)=22.1, p=.05, \mathrm{CFI}=.99, \mathrm{RMSEA}=$ $.069(90 \% \mathrm{CI}=.000-.118)$, and significant paths from depressive symptoms to peer-relevant cognition were found (see Figure 4). Earlier depressive symptom level was associated with lower positive peer-relevant cognition at later time points, with significant paths from $\mathrm{T} 1$ depressive symptoms to T2 peer relevant cognitions and from T2 depressive symptoms 


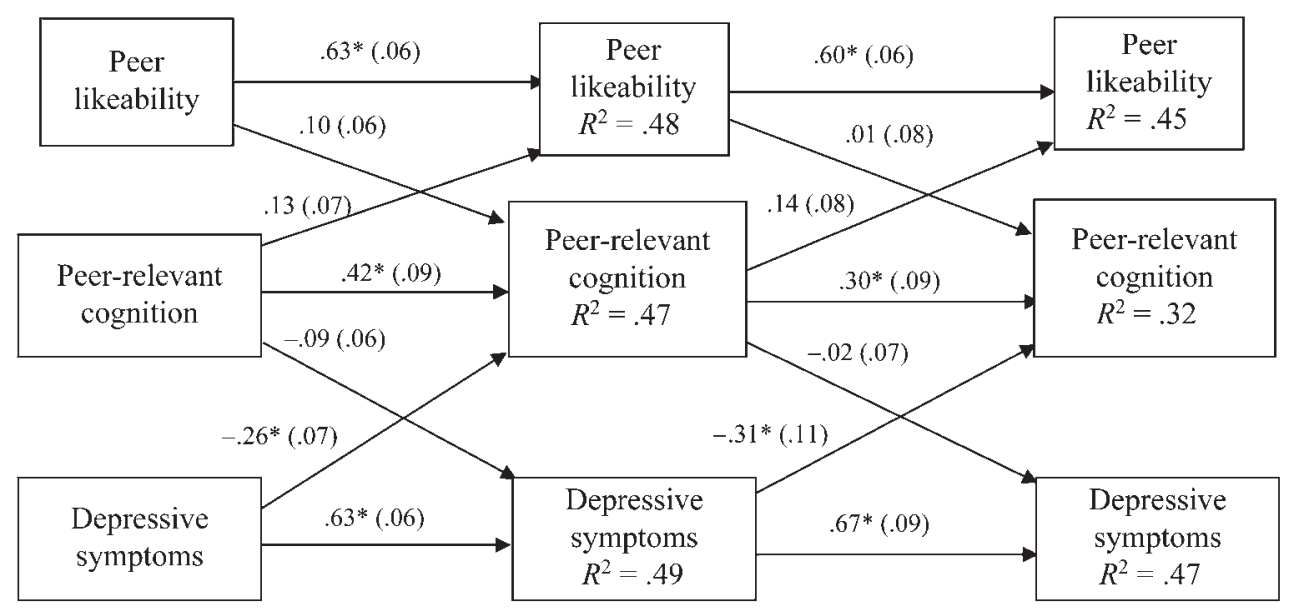

$\underline{\text { Time } 1(\mathrm{~T} 1)}$

$\underline{\mathrm{T} 2: 6 \text { months after T1 }}$

T3: 12 months after T2

Figure 4. The standardized path coefficients and bootstrapped standard errors of a path model testing a threewave bidirectional model of peer likeability, peer-relevant cognition, and depressive symptoms. $\chi^{2}(12, N=$ $146)=22.1, p=.05, \mathrm{CFI}=.99, \mathrm{RMSEA}=.069(90 \% \mathrm{CI}=.000$ to .118$) .{ }^{*} p<.01$.

to T3 peer-relevant cognition (standardized path coefficients $=-.26$ and -.31 , respectively, both $p<.01$ ). These findings are consistent with the two-wave model. There was no support for the significant associations within the cause portion of the model, which is also consistent with the two-wave model. Yet, in contrast to the two-wave model, there were no significant longitudinal associations between earlier peer-relevant cognition and later peer likeability in this threewave model. Although associations between earlier peer-relevant cognition and later peer likeability were similar in size when compared between the three-wave and the two-wave models, they were only marginally significant $(p<.10)$.

\section{Discussion}

A primary aim in the current study was to investigate a bidirectional model of linkages between being liked or disliked by classmates ( peer likeability), perceptions of acceptance and of peer relationships (peer-relevant cognition), and preadolescents' depressive symptoms. We also compared the fit of this model to a more parsimonious cause model of depressive symptoms, in which depression was only "caused by" stressful experiences of being less liked by peers via peerrelevant cognition, as well as an effects model with depression as the driver of degenerating thinking patterns and more stressful experiences. We expanded on these models to test whether correlational pathways differed by gender and age, and to examine whether negative peer-relevant cognition was an individual vulnerability that could exacerbate the association between peer problems and depressive symptoms.

Overall, findings showed that an effects model fit the data as well as a bidirectional model and provided the most parsimonious model. More specifically, a two-wave model of reciprocal (i.e., bidirectional) associations between peer likeability, peer-relevant cognition, and depressive symptoms provided a significantly better fit to the data than the cause model but not a significantly better fit than an effects model. When the first two waves of data were analyzed, peer-relevant cognition was concurrently correlated with depressive symptoms at each time point, and earlier depressive symptom level was associated with more negative peer-relevant cognition later, not the converse. In addition, peer likeability was significantly correlated with peer-relevant cognition within each time period (i.e., concurrently), and earlier peer-relevant cognition was associated with a higher level of peer likeability by $\mathrm{T} 2$ not the converse.

Children from the lowest two grades (Grades 5 and 6) also participated in a third wave of 
measurement, and a three-wave model was tested. The finding of temporal associations between self-reported depressive symptoms and peer-relevant cognition was supported over these 1.5 years. In contrast to the results with the larger sample and two waves of data, the association between earlier peer-relevant cognition and later peer likeability was found to be only marginally significant in this three-wave model. Findings from both models suggest that depressive symptoms can erode preadolescents' perceptions of their peer relationships over time. Yet, only findings from the twowave model show that a relatively more negative view of others is a significant antecedent of degenerating peer-relevant cognition and, in turn, peer likeability over time. These findings also show that there may be some influence of shared method variance in these models with associations between measures from the same reporter the only cross-lag associations that were strong enough to be replicated across both the twowave and the three-wave models.

Although all findings were not replicated across the two-wave and three-wave models, they do support a stress-generation model and a developmental psychopathology perspective, which both recognize how people negatively react to stress in the environment and, perhaps more importantly, construct and shape their social environments (Cicchetti \& Toth, 1995; see also Rudolph et al., 2000). These findings parallel research examining elaborated cognitive-interpersonal theories of depression pointing toward links between depressive symptoms in children/ preadolescents (e.g., Rudolph \& Clark, 2001) or adolescents (e.g., Hammen, Burge, Daley, \& Davila, 1995) and negative interpersonal perceptions, biased processing of interpersonal information, and maladaptive beliefs about relationships. In other studies with children or adolescents, a reciprocal process has been demonstrated in which an increase in negative cognitive style predicts increased depressive symptoms over time, and, as was found here, increased depressive symptoms predicted an increase in negative cognitive processing over time (Garber, Keiley, \& Martin, 2002). Moreover, research with children indicates that depressive symptoms may themselves undermine subsequent beliefs, leaving a cognitive "scar," thereby highlighting the ongoing transactions between vulnerability and depression that occurs across development (Cole et al., 1998; Nolen-Hoeksema, Girgus, \& Seligman, 1992; Pomerantz \& Rudolph, 2003). That preadolescents with relatively higher levels of depressive symptoms at $\mathrm{T} 1$ in this study showed relatively lower perceptions of acceptance and more negative views of their peers at later time points, may reflect on these types of transactions beginning prior to or at least by pre- to early adolescence (i.e., 9 to 13 years of age).

Key propositions of sociometer theory (Baumeister \& Leary, 1995) and self-concept developmental theory (Harter, 1999) were supported by significant cross-sectional associations between peer likeability, peer-relevant cognition, and depressive symptoms. However, these were not so clearly supported when analyses were extended to associations over time. Our findings of cross-sectional correlations suggest that peer likeability and preadolescents' thoughts about acceptance are concurrently negatively associated with depressive symptoms. Yet, the conception of depressive symptoms as an outcome of peer likeability and peer-relevant cognition was not supported in our examination of temporal associations. The current study findings are in contrast to the findings of Garber et al. (2002), in which a bidirectional model of cognitive styles and depressive symptoms was supported within an adolescent sample. Similarly, Cole, Martin, Powers, and Truglio (1996) empirically demonstrated through a longitudinal design that perception of social acceptance (referred to as social competence) is predictive of increasing depressive symptoms among students in third grade and sixth grade. This cause model is supported by other research, which has shown how measuring peer-relevant cognition adds to our understanding of how actual relationships are linked to well-being in children (e.g., Crick \& Ladd, 1993 ) and preadolescents or early adolescents (Rudolph \& Clark, 2001).

It is not clear why we failed to find support for a cause model. Possible reasons may be related to study methodology, such as participant age, the time lag between assessments, the measures used, or construct stability over time. It 
does not seem that age or time lag are likely explanations, however, as support for a cause model has been found within samples with a similar age range and with time lags similar to those used in the current study. We also found no evidence that path estimates differed for participants aged 9 to 10 compared to those ages 11 to 13 . Regarding the measures used in the current study, it may be that the measures of peer-relevant cognition explain our lack of support for a cause model. This explanation also does not seem to be a likely one, because previous research has used the same measures we have used here, with some results that conflict with those reported here (e.g., Rudolph \& Clark, 2001).

Another reason for the lack of support for a cause model may be the stabilities of the constructs over time. Finding temporal associations is more difficult because of the fairly high stability of depressive symptoms and the other constructs measured here (e.g., peer likeability). As others have described (Cole, NolenHoeksema, Girgus, \& Paul, 2006), stability of constructs can leave little additional variance to be accounted for by other variables. However, high construct stability does not seem to be a complete explanation for the findings, as significant associations were found that supported an effects model with small- to medium-sized effects, and the correlations between constructs over time were similar in this study when compared to previous research (see below). Overall, it may be the methodology used in the current study (e.g., the use of structural equation modeling to test covariances within each time, bidirectional associations and stabilities of constructs simultaneously, and the identification of parcels of items to improve assessment of relevant constructs) that allowed us to identify depressive symptoms as an antecedent of more negative peer-relevant cognition and, in turn, lower peer likeability rather than showing that depressive symptom level is an outcome of peer problems and negative peerrelevant cognition. In addition, because many studies of peer relationships and depressive symptoms have been conducted in North America, it is possible that the depressive symptoms of Australian preadolescents may follow a somewhat different course or may be less an outcome of peer relationships when compared to North American preadolescents. We encourage cross-national research to test such a possibility.

\section{Diathesis-Stress: Peer-Relevant Cognition as a Moderator}

Peer-relevant cognition also was considered as a potential moderator of the association between peer likeability and depressive symptoms. Using multiple analytical techniques, no significant moderator effect was found. These results are incongruous with some past findings (Abela, 2001; Dixon \& Ahrens, 1992; Panak \& Garber, 1992). As has been argued previously (Cole \& Turner, 1993), one explanation for a lack of support for a stress-diathesis model is the young age of the participants in the current study. Preadolescents and early adolescents (prior to Grade 8, about age 14) may not have developed the necessary stable diathesis for such an association to be found (Turner \& Cole, 1994). It is unclear whether such a possibility could fully account for the current study findings. Peer-relevant cognition had moderate stability over 6 months and 1 year in the current study, and there was little evidence that there was a significant difference in stability among younger (age 9-10) compared to older (age 11-13) participants.

Summarizing across these studies, the stability of peer-relevant cognition found in the current study is similar to that found in one study using the POPS with a similar aged sample (Caldwell et al., 1994; $r \mathrm{~s}=.38-.58$ ), and appears to be similar to or somewhat less stable than adolescents' peer-relevant cognition over similar or longer time lags (Kuperminc, Blatt, Shahar, Henrich, \& Leadbeater, 2004, $r=.62$; McGuireet al., 1999, $r=.43$; Steinberg, Lamborn, Darling, Mounts, \& Dornbusch, 1994, $r=.51$; Vernberg, $1990, r=.71)$. This is not consistent with the argument that the children or preadolescents in the current study have not yet developed a stable diathesis, but may suggest that their cognitions about peers are less stable than would be found in a similar longitudinal study of older adolescents. Nonetheless, these conclusions rely on the assumption that a stable diathesis can be revealed by a similar ranking across two repeated 
assessments, rather than, for example, using data collected more frequently to reveal variability and/or to estimate change trajectories over time (see Bolger, Davis, \& Raffaeli, 2003; Schneiders et al., 2006).

The use of peer likeability to measure stress is a more likely explanation for the null finding when peer-relevant cognition was tested as a moderator. To measure likeability, each student rated how much he/she liked each classmate. This measure would not be expected to tap all peer stressors, and may not even be the best measure of recent stressful peer-related events. Many studies that have supported a diathesis-stress model have focused on recent, specific and subjectively stressful events (see Hilsman \& Garber, 1995, for example). The measure of peer likeability is an objective assessment rather than a subjective appraisal of peer stress. Some researchers have examined both objective and subjective (or self-perceived) stress showing that it is stress perception and stress appraisal processes that have more impact on mental health than a life events checklist or other objective stress measures (Cole et al., 1998; Hoffman et al., 2000; Pomerantz \& Rudolph, 2003; Zimmer-Gembeck et al., 2007). Overall, it remains unclear whether a diathesisstress model better accounts for mental health problems among children, preadolescents, and/or older adolescents, applies to specific or a range of stressful domains, and whether objective stress is important to mental health in the short of the longer term regardless of whether children report their full awareness of their negative experiences. Such questions are worthy of continued cross-sectional and longitudinal research.

\section{Participant gender as a moderator}

Consistent with other studies of preadolescents (see Nolen-Hoeksema, 2001; NolenHoeksema \& Girgus, 1994, for reviews), we found no biological gender difference in depressive symptoms. Wealso examined whether associations between depressive symptoms and other measures differed for girls compared to boys, and found some evidence of gender differences in model pathways. In gen- eral, associations between peer-relevant cognition and depressive symptoms are more strongly contemporaneous for girls than for boys, and girls have more stable peer-relevant cognition and depressive symptoms than boys across a 6-month period.

In addition, contrary to expectations, but showing a gender difference similar to other recent research (Prinstein et al., 2005), two temporal associations were stronger among boys than girls when examined over a 6-month time period. The first of these temporal associations was from the "cause" portion of the model. Boys' peer likeability at T1 was associated with more positive peer-relevant cognition at T2, but this was not found for girls. The second of these temporal associations was from the "effects" portion of the model. Boys' depressive symptom level at $\mathrm{T} 1$ was more strongly negatively associated with peer-relevant cognition at $\mathrm{T} 2$ when compared with the association among girls. Overall, the model did not identify stronger associations among girls' compared to boys' peer likeability, peer-relevant cognition, and depressive symptoms. Instead, findings indicated that the intercorrelations of these factors are more contemporaneous among girls and more temporal among boys.

We do need to highlight that research findings from other groups suggest girls are more at risk of developing depression beginning at the transition to adolescence (for a review, see Prinstein et al., 2005; Rose \& Rudolph, 2006). This may be explained by a preexisting vulnerability in girls that increases their tendency to react to interpersonal stress (Petersen, Sarigiani, \& Kennedy, 1991). In a recent review, Rose and Rudolph (2006) summarized literature related to this proposition and proposed a model to account for gender differences in behavioral and emotional adjustment via peer relationship processes. Their review suggested that girls are more prosocial, have more conversations with social content, value social goals (e.g., having friends), worry more about social approval, are more exposed to some peer stressors (but not all), and are more likely to ruminate in response to stress when compared to boys. The current study is one response to their call to study these processes separately for girls and boys. However, our model deserves expansion to include specific processes that may differ for 
boys and girls. One approach would be to measure general peer likeability, as was done here, but also to include a greater range of objective and subjective stressors, such as direct victimization by peers (Lopez \& Dubois, 2005), stress within friendship groups, and intimate dyadic relationships. These have the potential to identify additional or more significant differences between boys and girls.

\section{Participant age as a moderator}

Many studies have documented increasing depressive symptoms at ages 12 to 14 (e.g., Wichstron, 1999), and higher levels of depressive symptoms among girls than boys from around age 13 (Nolen-Hoeksema \& Girgus, 1994). The average participant in the current study appears to have been slightly too young (age 11) to capture age-related increases or gender differences. We also found very little evidence of differing model pathways for younger (ages 9-10) compared to older (ages 11-13) participants. In the future, researchers may find it promising to use a cross-sectional sequential design (Baltes, Reese, \& Nesselroade, 1988) to compare patterns across time in the preadolescent age group included here to a slightly older group.

\section{Study limitations and strengths}

Most analyses depended upon two waves of data collected over 6 months. This short time period may have been a study limitation. Whether a 6month lag of time was enough to determine precursors of change in depressive symptoms is unclear. However, the choice of a 6-month time lag allowed for comparisons with other developmental studies that have similarly employed relatively short time lags (e.g., Caldwell et al., 2004; Crick, 1996; Panak \& Garber, 1992) and the extension to a smaller sample followed a year after the T2 assessment further supported some key findings in the two-wave models.

It is important to acknowledge that the longitudinal associations found here were small to moderate in magnitude, and associations between self-report measures were stronger than those between measures gathered via different reporters. These results raise two questions. First, there is the question of whether a 6-month time lag was the optimum period to allow for differences or changes and for testing of the predicted associations among variables (see Cole \& Maxwell, 2003). Nonetheless, some longitudinal findings did emerge and all were above and beyond the high stability of constructs and strong cross-sectional associations. Second, there is the question of whether shared method variance may have inflated some model pathways. Data were gathered via both peerand self-report to improve data quality and to reduce the possibility of shared method variance. Nevertheless, self-report measures of depression symptoms and peer-relevant cognition were used, so the strength of these associations may have been inflated to some extent. Future research that includes multiple sources of information for all components in our model will assist in determining how much shared method variance might have influenced results.

Another study limitation is the use of one selfreport measure of depressive symptoms and the use of parcels of items from the self-report CDI to indicate a latent construct of depressive symptoms in the two-wave model. This limitation could be overcome in the future by collecting reports of depressive symptoms from teachers, parents, and/or peer reports, although accuracy of such reports have been inconsistent, and may vary as a function of gender and familiarity with the reporter (Swenson \& Rose, 2003).

\section{Conclusions}

To summarize the current study findings, depressive symptoms are concurrently associated with students' reports of how much they like their classmates and preadolescents' views of their peers and their social acceptance (peer-relevant cognition). More importantly, preadolescents' depressive symptom level precedes less positive peer-relevant cognition rather than the converse. In addition, more positive perceptions of peer relationships and social acceptance are antecedents of how much preadolescents are liked or disliked by their classmates 6 months later. There also are some differences in the pathways for boys compared to girls, with some longitudinal associations stronger for boys than girls, some concurrent associations stronger for girls than boys, and one path from the cause model emerging for boys but not girls. 
When the current study findings are considered along with related theory and research, it appears that, just like in later life, preadolescents' depressive symptoms interfere with adaptive cognitions about others, and these cognitions rather than depressive symptoms interfere with peer relationships. These depressive symptoms also may extend to other cognitive vulnerabilities and biases, such as memory biases for negative self-referent information (Garber \& Kaminski, 2000) and a pervasive focus on negative rather than positive interactions with others (Cole et al., 1998; Garber et al., 2002; Nolen-Hoeksema et al., 1992;

\section{References}

Abela, J. R. Z. (2001). The hopelessness theory of depression: A test of the diathesis-stress and causal mediation components in third to seventh grade children. Journal of Abnormal Child Psychology, 29, 241-254.

Alloy, L. B., Abramson, L. Y., \& Francis, E. L. (1999). Do negative cognitive styles confer vulnerability to depression? Current Directions in Psychological Science, 8 , 128-132.

Asher, S. R., \& Dodge, K. A. (1986). Identifying children who are rejected by their peers. Developmental Psychology, 22, 444-449.

Bagwell, C. L., Schmidt, M. E., Newcomb, A. F., \& Bukowski, W. M. (2001). Friendship and peer rejection as predictors of adult adjustment. New Directions for Child and Adolescent Development, 91, 25-49.

Baltes, P. B., Reese, H. W., \& Nesselroade, J. R. (1988). Life-span developmental psychology: Introduction to research methods. Hillsdale, NJ: Erlbaum.

Baumeister, R. F., \& Leary, M. R. (1995). The need to belong: Desire for interpersonal attachments as a fundamental human motivation. Psychological Bulletin, 117, 497-529.

Bentler, P. M., \& Bonett, D. G. (1980). Significance tests and goodness-of-fit in the analysis of covariance structures. Psychological Bulletin, 88, 588-606.

Berndt, T. J. (1996). Exploring the effects of friendship quality on social development. In W. M. Bukowski, A. F. Newcomb, \& W. W. Hartup (Eds.), The company they keep: Friendship in childhood and adolescence (pp. 346-365). New York: Cambridge University Press.

Berndt, T. J. (2004). Children's friendships: Shifts over a half-century in perspectives on their development and their effects. Merrill-Palmer Quarterly, 50, 206-233.

Bierman, K. (2003). Peer rejection. New York: Guilford Press.

Birmaher, B., Ryan, N. D., Williamson, D. E., Brent, D. A., Kaufman, J., Dahl, R. E., et al. (1996). Childhood and adolescent depression: A review of the past 10 years. Journal of the American Academy of Child \& Adolescent Psychiatry, 35, 1427-1439.

Boivin, M., Poulin, F., \& Vitaro, F. (1994). Depressed mood and peer rejection in childhood. Development and Psychopathology, 6, 483-498.

Bolger, N., Davis, A., \& Raffaeli, E. (2003). Diary methods: Capturing life as it is lived. Annual Review of Psychology, 54, 579-616.
Pomerantz \& Rudolph, 2003). This makes it important to continue the study of actual and perceived peer relationships along with behaviors and internalizing symptoms within many age periods and among boys and girls. Such studies will allow tests of different directions of influence within different age periods and help to determine whether and when the direction of influence might change from depressive symptoms as an outcome of social experience and related cognitions to depressive symptoms as an antecedent of increasing stress, negative social experiences, and other individual difficulties.

Browne, M. W., \& Cudeck, R. (1993). Alternative ways of assessing model fit. In K. A. Bollen \& J. S. Long (Eds.), Testing structural equation models (pp. 136-162). Thousand Oaks, CA: Sage.

Bukowski, W. M. (2001). Friendship and the worlds of childhood. New Directions for Child and Adolescent Development, 91, 93-105.

Bukowski, A. L., \& Adams, R. (2005). Peer relationships and psychopathology: Markers, moderators, mediators, mechanisms, and meanings. Journal of Clinical Child and Adolescent Psychology, 34, 3-10.

Caldwell, M. S., Rudolph, K. D., Troop-Gordon, W., \& Kim, D. Y. (2004). Reciprocal influences among relational self-views, social disengagement, and peer stress during early adolescence. Child Development, 75, 1140-1154

Cicchetti, D., \& Toth, S. L. (1995). Developmental psychopathology and disorders of affect. In D. Cicchetti \& D. J. Cohen (Eds.), Developmental psychopathology: Risk, disorder, and adaptation (Vol. 2, pp. 369-420). New York: Wiley.

Cicchetti, D., \& Toth, S. L. (1998). The development of depression in children and adolescents. American Psychologist, 53, 221-241.

Cillessen, A. H. N., \& Bukowski, W. M. (Eds.). (2000). Recent advances in the measurement of acceptance and rejection in the peer system. San Francisco, CA: Jossey-Bass.

Cole, D. A., Martin, J. M., Peeke, L. G., Serocsynski, A. D., $\&$ Hoffman, K. (1998). Are cognitive errors of underestimation predictive or reflective of depressive symptoms in children: A longitudinal study. Journal of Abnormal Psychology, 107, 481-496.

Cole, D. A., Martin, J. M., Powers, B., \& Truglio, R. (1996). Modelling causal relations between academic and social competence and depression: A multitrait-multimethod longitudinal study of children. Journal of Abnormal Psychology, 105, 258-270.

Cole, D. A., \& Maxwell, S. E. (2003). Testing mediational models with longitudinal data: Questions and tips in the use of structural equation modeling. Journal of Abnormal Psychology, 112, 558-577.

Cole, D. A., Nolen-Hoeksema, S., Girgus, J., \& Paul, G. (2006). Stress exposure and stress generation in child and adolescent depression: A latent trait-state-error 
approach to longitudinal analyses. Journal of Abnormal Psychology, 115, 40-51.

Cole, D. A., \& Turner, J. E., Jr. (1993). Models of cognitive mediation and moderation in child development. Journal of Abnormal Psychology, 102, 271-281.

Coyne, J. C. (1976). Toward an interactional description of depression. Psychiatry, 39, 28-40.

Coyne, J. C., \& Whiffen, V. E. (1995). Issues in personality as diathesis for depression: The case of sociotrophy-dependency and autonomy-self criticism. Psychological Bulletin, 118, 358-378.

Crick, N. R. (1996). The role of overt aggression, relational aggression, and prosocial behavior in the prediction of children's future social adjustment. Child Development, 67, 2317-2327.

Crick, N. R., \& Dodge, K. (1994). A review and reformulation of social information-processing mechanisms in children's social adjustment. Psychological Bulletin, $115,74-113$.

Crick, N. R., \& Ladd, G. W. (1993). Children's perceptions of their peer experiences: Attributions, loneliness, social anxiety, and social avoidance. Developmental Psychology, 29, 244-254.

Crick, N., \& Zahn-Waxler, C. (2003). The development of psychopathology in females and males: Current progress and future challenges. Development and Psychopathology, 15, 719-742.

Cyranowski, J. M., Frank, E., Young, E., \& Shear, K. (2000). Adolescent onset of the gender difference in lifetime rates of major depression: A theoretical model. Archives of General Psychiatry, 57, 21-27.

Davila, J., Ramsay, M., Stroud, C. B., \& Steinberg, S. J. (2005). Attachment as vulnerability to the development of psychopathology. In B. L. Hankin \& J. R. Z. Abela (Eds.), The development of psychopathology: A vulnerability-stress perspective (pp. 215-242). Thousand Oaks, CA: Sage.

DeRosier, M. E., \& Thomas, J. M. (2003). Strengthening sociometric prediction: Scientific advances in the assessment of children's peer relations. Child Development, 75, 1379-1392.

Dixon, J. F., \& Ahrens, A. H. (1992). Stress and attributional style as predictors of self-reported depression in children. Cognitive Therapy and Research, 16, 623634.

Feldman, S. S., \& Elliott G. R. (Eds.). (1990). At the threshold: The developing adolescent. Cambridge, MA: Harvard University Press.

Furman, W., \& Buhrmester, D. (1992). Age and sex differences in perceptions of networks of personal relationships. Child Development, 63, 103-115.

Garber, J., \& Kaminski, K. M. (2000). Laboratory and performance-based measures of depression in children and adolescents. Journal of Clinical Child Psychology, 29, $509-525$.

Garber, J., Keiley, M. K, \& Martin, N. C. (2002). Developmental trajectories of adolescents' depressive symptoms: Predictors of change. Journal of Consulting and Clinical Psychology, 70, 79-95

Gibb, B. E., Alloy, L. B., Abramson, L. Y., Beevers, C. G., \& Miller, I. W. (2004). Cognitive vulnerability to depression: A taxometric analysis. Journal of Abnormal Psychology, 113, 81-89.

Gleicher, F., \& Weary, G. (1991). Effect of depression on quantity and quality of social inferences. Journal of Personality and Social Psychology, 61, 105-114.

Hammen, C. L. (2005). Stress and depression. Annual Review of Clinical Psychology, 1, 293-319.
Hammen, C. L., Burge, D., Daley, S. E., \& Davila, J. (1995). Interpersonal attachment cognitions and prediction of symptomatic responses to interpersonal stress. Journal of Abnormal Psychology, 104, 436-443.

Harter, S. (1982). The Perceived Competence Scale for Children. Child Development, 53, 87-97.

Harter, S. (1990). Causes, correlates, and the functional role of global self-worth: A life span perspective. In R. J. Sternberg \& J. Kolligian (Eds.), Competence considered (pp. 67-97). New Haven, CT: Yale University Press.

Harter, S. (1999). The construction of the self: A developmental perspective. New York: Guilford Press.

Harter, S., \& Whitesell, N. R. (1996). Multiple pathways to self-reported depression and psychological adjustment among adolescents. Development and Psychopathology, 8, 761-777.

Hartup, W. W. (1989). Social relationships and their developmental significance. American Psychologist, 44, 120-126.

Hecht, D. B., Inderbitzen, H. M., \& Bukowski, A. L. (1998). The relationship between peer status and depressive symptoms in children and adolescents. Journal of Abnormal Child Psychology, 26, 153-160.

Hilsman, R., \& Garber, J. (1995). A test of the cognitive diathesis-stress model of depression in children: Academic stressors, attributional style, perceived competence, and control. Journal of Personality and Social Psychology, 69, 370-380.

Hoffman, K. B., Cole, D. A., Martin, J. M., Tram, J., \& Seroczynski, A. D. (2000). Are the discrepancies between self- and others' appraisals of competence predictive or reflective of depressive symptoms in children and adolescents: A longitudinal study, part II. Journal of Abnormal Psychology, 109, 651-662.

Hu, L., \& Bentler, P. M. (1999). Cutoff criteria for fit indexes in covariance structure analysis: Conventional criteria versus new alternatives. Structural Equation Modeling, 6, 1-55.

Hymel, S., Rubin, K. H., Rowden, L., \& LeMare, L. (1990). Children's peer relationships: Longitudinal prediction of internalizing and externalizing problems from middle to late childhood. Child Development, 61, 2004-2021.

Jaccard, J., Turrisi, R., \& Wan, C. K. (1990). Interaction effects in multiple regression. Newbury Park, CA: Sage.

Jaccard, J., \& Wan, C. K. (1995). LISREL approaches to interaction effects in multiple regression. Newbury Park, CA: Sage.

Joiner, T. E. Jr. (1995). The price of soliciting and receiving negative feedback: Self-verification theory as a vulnerability to depression theory. Journal of Abnormal Psychology, 104, 364-372.

Joiner, T. E. Jr. (2000). Depression's vicious scree: Selfpropagating and erosive processes in depression chronicity. Clinical Psychology: Science and Practice, 7, 203-218.

Joiner, T. E. Jr., Wingah, L., Gencoz, T., \& Gencoz, F. (2005). Stress generation in depression: Three studies on its resilience, possible mechanism, and symptom specificity. Journal of Social and Clinical Psychology, 24, 236-253.

Kaplan, D. (2000). Structural equation modeling: Foundations and extensions. Thousand Oaks, CA: Sage.

Kistner, J. A., David-Ferdon, C. F., Repper, K. K., \& Joiner, T. E. (2006). Bias and accuracy of children's perceptions of peer acceptance: Prospective associations with depressive symptoms. Journal of Abnormal Child Psychology, 34, 349-361. 
Kovacs, M. (1985). The Children's Depression Inventory. Psychopharmacology Bulletin, 21, 995-998.

Kuperminc, G. P., Blatt, S. J., Shahar, G., Henrich, C., \& Leadbeater, B. J. (2004). Cultural equivalence and cultural variance in longitudinal associations of young adolescent self-definition and interpersonal relatedness to psychological and social adjustment. Journal of Youth and Adolescence, 33, 13-30.

Landis, R. S., Beal, D. J., \& Tesluk, P. E. (2000). A comparison of approaches to forming composite measures in structural equation models. Organizational Research Methods, 3, 186-207.

Leary, M. R., \& Downs, D. L. (1995). Interpersonal functions of the self-esteem motive: The self-esteem system as a sociometer. In M. Kernis (Ed.), Efficacy, agency, and selfesteem (pp. 123-144). New York: Plenum Press.

Leary, M. R., Schreindorfer, L. S., \& Haupt, A. L. (1999). The role of low self-esteem in emotional and behavioral problems: Why is low self-esteem dysfunctional? Journal of Social and Clinical Psychology, 14, 297-314.

Levendosky, A. A., Okun, A., \& Parker, J. G. (1995). Depression and maltreatment as predictors of social competence and social problem solving skills in schoolage children. Child Abuse and Neglect, 19, 1183-1195.

Little, T. D., Cunningham, W. A., Shahar, G., \& Widaman, K. F. (2002). To parcel or not to parcel: Exploring the question, weighing the merits. Structural Equation Modeling, 9, 151-173.

Lopez, C., \& DuBois, D. L. (2005). Peer victimization and rejection: Investigation of an integrative model of effects on emotional, behavioral, and academic adjustment in early adolescence. Journal of Clinical Child and Adolescent Psychology, 34, 25-36.

Martin, J. M., Cole, D. A., Clausen, A., Logan, J., \& Strosher, H. L. W. (2003). Moderators of the relation between popularity and depressive symptoms in children: Processing strength and friendship value. Journal of Abnormal Child Psychology, 31, 471-483.

McGuire, S., Manke, B., Saudino, K. J., Reiss, D., Hetherington, E. M., \& Plomin, R. (1999). Perceived competence and self-worth during adolescence: A longitudinal behavioral genetic study. Child Development, 70, 1283-1296.

Moran, P. B., \& Eckenrode, J. (1991). Gender differences in the costs and benefits of peer relationships during adolescence. Journal of Adolescent Research, 6, 396-409.

Nolen-Hoeksema, S. (2001). Gender differences in depression. Current Directions in Psychological Science, 10, 173-176.

Nolen-Hoeksema, S., \& Girgus, J. S. (1994). The emergence of gender differences in depression during adolescence. Psychological Bulletin, 115, 424-443.

Nolen-Hoeksema, S., Girgus, J. S., \& Seligman, M. E. (1992). Predictors and consequences of childhood depressive symptoms: A 5-year longitudinal study. Journal of Abnormal Psychology, 101, 405-422.

Oldehinkel, A. J., Rosmalen, J. G. M., Veenstra, R., Kornelis Dijkstra, J., \& Ormel, J. (2007). Being admired or being liked: Classroom social status and depressive problems in early adolescent girls and boys. Journal of Abnormal Child Psychology, 35, 417-427.

Panak, W. F., \& Garber, J. (1992). Role of aggression, rejection, and attributions in the prediction of depression in children. Development and Psychopathology, 4, 145165.

Parker, J. G., Rubin, K. H., Price, J. M., \& DeRosier, M. E. (1995). Peer relationships, child development, and adjustment: A developmental psychopathology perspective.
In D. Cicchetti \& D. J. Cohen (Eds.), Developmental psychopathology: Risk, disorder, and adaptation (Vol. 2, pp. 96-161). New York: Wiley.

Petersen, A. C., Sargiani, P. A., \& Kennedy, R. E. (1991). Adolescent depression: Why more girls? Journal of Youth and Adolescence, 20, 247-271.

Pomerantz, E. M., \& Rudolph, K. D. (2003). What ensues from emotional distress? Implications for competence estimation. Child Development, 74, 329-345.

Prinstein, M. J., Borelli, J. L., Cheah, C. S. L., Simon, V. A., \& Wargo Aikins, J. (2005). Adolescent girls' interpersonal vulnerability to depressive symptoms: A longitudinal examination of reassurance-seeking and peer relationships. Journal of Abnormal Psychology, 114, 676-688.

Rose, A. J., \& Rudolph, K. D. (2006). A review of sex differences in peer relationship processes: Potential tradeoffs for the emotional and behavioral development of girls and boys. Psychological Bulletin, 132, 98-131.

Rudolph, K. D. (2002). Gender differences in emotional responses to interpersonal stress during adolescence. Journal of Adolescent Health, 30, 3-13.

Rudolph, K. D., \& Asher, S. R. (2000). Adaptation and maladaptation in the peer system: Developmental processes and outcomes. In A. J. Sameroff \& M. Lewis (Eds.), Handbook of developmental psychopathology (2nd ed., pp. 157-175). Dordrecht: Kluwer.

Rudolph, K. D., \& Clark, A. G. (2001). Conceptions of relationships in children with depressive and aggressive symptoms: Social-cognitive distortion or reality? Journal of Abnormal Child Psychology, 29, 41-56.

Rudolph, K. D., Hammen, C., \& Burge, D. (1994). Interpersonal functioning and depressive symptoms in childhood: Addressing the issues of specificity and comorbidity. Journal of Abnormal Child Psychology, 22, 355-371.

Rudolph, K. D., Hammen, C., \& Burge, D. (1995). Cognitive representations of self, family, and peers in school-age children: Links with social competence and sociometric status. Child Development, 66, 1385-1402.

Rudolph, K. D., Hammen, C., \& Burge, D. (1997). A cognitive-interpersonal approach to depressive symptoms in preadolescent children. Journal of Abnormal Child Psychology, 25, 33-45.

Rudolph, K. D., Hammen, C., Burge, D., Lindberg, N., Herzberg, D., \& Daley, S. E. (2000). Toward an interpersonal life-stress model of depression: The developmental context of stress generation. Development and Psychopathology, 12, 215-234.

Rutter, M., Dunn, J., Plomin, R., Simonoff, E., Pickles, A., Maughan, B., et al. (1997). Integrating nature and nurture: Implications of person-environment correlations and interactions for developmental psychopathology. Development and Psychopathology, 9, 335-364.

Sacco, W. P., \& Dunn, V. K. (1990). Effect of actor depression on observer attributions: Existence and impact of negative attributions toward the depression. Journal of Personality and Social Psychology, 59, 517-524.

Schneiders, J., Nicolson, N. A., Berkhof, J., Feron, F. J., Os, J. V., \& deVries, M. W. (2006). Mood reactivity to daily negative events in early adolescence: Relationship to risk for psychopathology. Developmental Psychology, 42, 543-554.

Segrin, C. (2001). Interpersonal processes in psychological problems. New York: Guilford Press.

Shrout, P. E., \& Bolger, N. (2002). Mediation in experimental and nonexperimental studies: New procedures and recommendations. Psychological Methods, 7, $422-445$. 
SmallWaters Corporation. (1999). AMOS 4.0 user's guide. Chicago: Author.

Steinberg, L., Lamborn, S. D., Darling, N., Mounts, N. S., \& Dornbusch, S. M. (1994). Over-time changes in adjustment and competence among adolescents from authoritative, authoritarian, indulgent, and neglectful families. Child Development, 65, 754-770.

Swenson, L. P., \& Rose, A. J. (2003). Friends as reporters of children's and adolescents' depressive symptoms. Jour nal of Abnormal Child Psychology, 31, 619-631.

Tabachnick, B. G., \& Fidell, L. S. (2001). Using multivariate statistics (4th ed.). Boston: Allyn \& Bacon.

Turner, J. E., \& Cole, D. A. (1994). Developmental differences in cognitive diathesis for child depression. Journal of Abnormal Child Psychology, 22, 15-32.

Vernberg, E. M. (1990). Psychological adjustment and experiences with peers during early adolescence: Reciprocal, incidental, or unidirectional relationships? Journal of Abnormal Child Psychology, 18, 187-198.

Weinstock, L. M., \& Whisman, M. A. (2004). The self-verification model of depression and interpersonal rejec- tion in heterosexual dating relationships. Journal of Social and Clinical Psychology, 23, 240-259.

Weisz, J. R., Rudolph, K. D., Granger, D. A., \& Sweeney, L. (1992). Cognition, competence, and coping in child and adolescent depression: Research findings, developmental concerns, therapeutic implications. Development and Psychopathology, 4, 627-653.

Wichstrom, L. (1999). The emergence of gender difference in depressed mood during adolescence: The role of intensified gender socialization. Developmental Psychology, 35, 232-245.

Zimmer-Gembeck, M. J., Chipuer, H. M., Hanisch, M., Creed, P. A., \& McGregor, L. (2006). Relationships at school and environmental fit as resources for adolescent engagement and achievement. Journal of Adolescence, 29, 911-933.

Zimmer-Gembeck, M. J., Hunter, T. A., \& Pronk, R. (2007). A model of behaviors, peer relations and depression: Perceived social acceptance as a mediator and the divergence of perceptions. Journal of Social and Clinical Psychology, 26, 273-283. 